${ }^{1}$ Centro Universitário Newton Paiva, Silva Lobo Avenue, 1730 Grajaú. Zip Code 30411-335. Belo Horizonte, MG - Brazil.
Corresponding author:

Lidiane Cristina Machado Costa Department of Periodontics, School of Dentistry,

Centro Universitário Newton Paiva Silva Lobo Avenue, 1730 - Grajaú Zip Code 30411-335

Belo Horizonte, MG - Brazil

Phone: 5531991836684

E-mail: lidiane.cmachadocosta@gmail.com

Received: March 02, 2020

Accepted: June 13, 2020

\section{Comparative analysis of the surface roughness of conventional resins and filling after immersion in mouthwashes}

\author{
Juliana de Souza Silva Zica' ${ }^{10}$, Isabela Araújo \\ Fernandes ${ }^{1}$ (D) , Fernanda Barcellos Ameno Faria ${ }^{1}$ (D) , \\ Fernanda Cruz Ferreira' (1D) , Nívea Aparecida Reis \\ Albuquerque $^{1}$ (D) , José Flávio Batista Gabrich \\ Giovannini ${ }^{1}$ (D) , Lidiane Cristina Machado Costa ${ }^{1, *}$ (D)
}

Aim: Bulk Fill composite resins were released on the market in order to reduce the time in clinical sessions by using increments of up to $5.0 \mathrm{~mm}$ thickness. The aim of this study was to evaluate the effect of the rinsing solutions on the surface roughness of the conventional composite and Bulk fill composite resins. Methods: 40 specimens were prepared from a $4.0 \mathrm{~mm} \times 10.0 \mathrm{~mm}$ teflon matrix and photoactivated for 20 seconds, with 20 specimens made of Filtek Bulk-Fill composite resin (3M ESPE) and 20 specimens made with Filtek ${ }^{\mathrm{TM}}$ Z350 XT composite resin (3M ESPE). Each group was subdivided into 2 subgroups: G1 (Filtek ${ }^{\text {TM }}$ Z350 XT-3M ESPE-immersed in Colgate PlaxWhitening®); G2 (Filtek ${ }^{\text {TM }}$ Z350 XT-3M ESPE-immersed in PlaxFreshMint $®$ ); G3 (Filtek ${ }^{\text {TM }}$ Bulk-Fill-3M ESPE-immersed in Colgate PlaxWhitening ${ }^{\circledR}$ ) and G4 (Filtek ${ }^{\mathrm{TM}}$ Bulk-Fill-3M ESPE-immersed in Colgate PlaxFreshMint $\circledast$ ). The surface roughness test was performed initially and after immersion in rinses by the Time Group Inc.TR200® rugosimeter apparatus and the data were submitted to statistical analysis (two-way repeated measures ANOVA) Results: Surface roughness values of the Filtek ${ }^{\text {TM }}$ Bulk-Fill composite resin (3M ESPE) were significantly higher than the Filtek ${ }^{\mathrm{TM}}$ Z350 XT composite resin (3M ESPE) $(\mathrm{P}<0.0001)$. However, no differences were identified before and after immersion in rinses with or without alcohol. Conclusion: The use of mouthwashes does not interfere with the surface roughness of the tested resins, but the composite resin Filtek Z350 XT (3M ESPE) presents a surface with less roughness.

Keywords: Compositeresins. Materials testing. Mouthwashes. Surface properties. 


\section{Introduction}

Composite resins are restorative materials extensively used in Dentistry due to their excellent aesthetic ${ }^{1}$ physical and mechanical properties, which allows the reproduction of characteristics similar to dental structures ${ }^{2}$ as well as minimal removal of healthy dental structure. The popularity of the composite resins arises from their outstanding adhesiveness and the ability to mimic oral tissues. However, the insertion of composite resins into the cavity requires more clinical time, since the incremental technique is the most appropriate ${ }^{3}$. Typically, this technique consists of adding composite resin increments up to $2.0 \mathrm{~mm}$ thick, followed by exposure to the photoactivator until the cavity is entirely filled ${ }^{4}$. Driven by consumer demand for faster, more straightforward procedures and reduced clinical time, the market has recently launched a new category of fillers for posterior teeth know as bulk-fill composite resin. Said resin allows the insertion of up to $4.0 \mathrm{~mm}$ thick increments without too much polymerization shrinkage ${ }^{5}$. Said decreased polymerization shrinkage derives from properties capable of reducing the contraction stress and increasing the pre-gel phase, which is characterized by more flexible polymer chains, allowing the material to flow freely through the cavity surface ${ }^{6}$. Moreover, these materials provide higher transmission of light, thus allowing the reach of greater polymerization depth 6 .

Notwithstanding the recommended optimization of the clinical time, some deficiencies of composite resins concerning aesthetic properties, such as color change and translucency, must be considered. These aesthetic properties can be influenced by the surface roughness of the restorations as well as by the oral conditions in which they are inserted ${ }^{7}$. As a result of this interaction, mainly by contact with substances containing dyes, extrinsic staining occurs through the absorption of pigments from exogenous factors associated with individuals' habits, food, and use of mouthwashes ${ }^{8}$. Thus, the properties of the composite resins can be changed by environmental conditions, considering that the exposure to acid solutions contained in the buccal cavity can influence the surface gloss and hardness, which causes degradation of the materials and reduces their clinical longevity. This process allows plaque retention, wear and staining of the restorations ${ }^{9}$.

Mouthwashes help to control the biofilm and serve as a complement for the patient's toothbrushing. The mouthwashes have been widely used, even without professional prescription ${ }^{10,11}$. Such products have varied compositions and ingredients that can also cause degradation, softening, and wear of composite resins ${ }^{7}$, making the surface irregular and exposed to bacterial plaque retention. The composition of these products consists of water, antimicrobial agents, salts, and, in some cases, alcohol. The antiseptics $\mathrm{pH}$ may be affected as a result of the different concentrations of these substances. Despite the frequent use of these products, the effects of such components on the composite resin polymer matrix have not been widely discussed ${ }^{9}$.

Besides, changes along the inorganic phase may decrease the physical properties of the material, such as microhardness and roughness ${ }^{11}$. In contrast, the effect of rinses on wear and hardness also depends on the material that is analyzed. Differences in chemical composition, type, and filler content are accountable for this variation. More- 
over, the chemical alteration of the restoration surface cannot be attributed to a single chemical component, but it is otherwise the result of complex reactions between the different chemical composites ${ }^{12}$.

The literature on the surface roughness of bulk-fill composite resins is still scarce. The literature does not indicate whether changes in the composition of materials tend to affect the surface roughness and whether chemical compounds, such as mouthwashes, can adversely affect the integrity of their surface. Further researches should be carried out about changes in the surface of these composite resins. These composite resins must have a smooth surface to increase durability, improve aesthetic appearance, and avoid color changes in the restoration ${ }^{13-18}$.

Therefore, this study aims to evaluate the effect of the rinsing solutions on the surface roughness of the conventional composite and bulk-fill composite resins.

\section{Materials and Methods}

This experiment consists of the surface roughness comparison test between Filtek ${ }^{\text {TM }}$ Bulk-fill composite resins (3M ESPE) and Filtek ${ }^{\text {TM }}$ Z350 XT composite resins (3M ESPE), both with the same nanoparticle technology, after immersion in mouthwashes, either with or without alcohol. Table 1 provides the characteristics of the composite resins used. The analyses were carried out in the Material Engineering Laboratory of the Centro Universitário Newton Paiva, in the State of Belo Horizonte, Brazil.

Table 1. Characteristics of the composite resins used.

\begin{tabular}{|c|c|c|c|c|c|}
\hline Material & Type/Color & $\begin{array}{c}\text { Organic } \\
\text { Composition }\end{array}$ & $\begin{array}{l}\text { Inorganic } \\
\text { Load }\end{array}$ & $\begin{array}{l}\text { Average } \\
\text { Size }\end{array}$ & Manufacturer \\
\hline Filtek Z350 XT & A2 ENAMEL & $\begin{array}{l}\text { BIS-GMA*, } \\
\text { UDMA }{ }^{* \star}, \\
\text { TEGDMA } \\
\text { BIS-EMA* }\end{array}$ & $\begin{array}{c}78.5 \% \text { by weight } \\
\text { or } 63.3 \% \text { by } \\
\text { volume }\end{array}$ & $\begin{array}{c}10 \text { to } 20 \\
\text { nanometers }\end{array}$ & 3M ESPE \\
\hline Filtek Bulk-fill & $\mathrm{A} 2$ & $\begin{array}{l}\text { AUDMA q, } \\
\text { AFM १q, } \\
\text { UDMA } \\
\text { DDMA q৭ }\end{array}$ & $\begin{array}{c}76.5 \% \text { by weight } \\
\text { or } 58.4 \% \text { by } \\
\text { volume }\end{array}$ & $\begin{array}{c}10 \text { to } 20 \\
\text { nanometers }\end{array}$ & 3M ESPE \\
\hline
\end{tabular}

* Bisphenolglycidyl methacrylate

** Urethane dimethacrylate

*** Triethylene glycol dimethacrylate

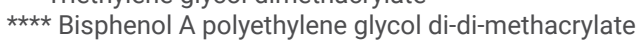

9 Aromatic dimethacrylate urethane

१ฯ Additional fragmentation monomer

१ฯฯ Dodecanedimetacrylate

The specimens were prepared using a polished Teflon ${ }^{\text {TM }}$ matrix of $4.0 \mathrm{~mm}$ depth and 10.0 mm internal diameter ${ }^{15,19-22}$ in which the composite resin was added. Thus, 20 specimens were prepared using Filtek ${ }^{\mathrm{TM}}$ Bulk-Fill composite resin (3M ESPE), and the other 20 specimens used Filtek ${ }^{\mathrm{TM}} \mathrm{Z350}$ XT composite resin (3M ESPE). These specimens were divided into four groups: (i) G1- Filtek ${ }^{\mathrm{TM}}$ Bulk-Fill composite resins 
(3M ESPE) immersed in the Colgate PlaxWhitening ${ }^{\text {TM }}$ mouthwash; (ii) G2- Filtek ${ }^{\text {TM }}$ Bulk-Fill composite resins (3M ESPE) immersed in Colgate PlaxFreshMint ${ }^{\mathrm{TM}}$ mouthwash; (iii) G3- Filtek ${ }^{\text {TM }}$ Z350 XT composite resin (3M ESPE) immersed in the ColgatePlaxWhitening ${ }^{\text {TM }}$ mouthwash; and (iv) G4- Filtek ${ }^{\text {TM }}$ Z350 XT composite resins (3M ESPE) immersed in the Colgate PlaxFreshMint ${ }^{\text {TM }}$ mouthwash. Table 2 provides the characteristics of the mouthwashes used in tests.

Table 2. Characteristics of the used mouthwashes.

\begin{tabular}{lccc}
\hline Brand & Type & Composition & Manufacturer \\
\hline $\begin{array}{l}\text { Colgate Plax } \\
\text { Whitening }\end{array}$ & $\begin{array}{c}\text { Solution } \\
\text { Antiseptic }\end{array}$ & $\begin{array}{r}\text { Hydrogen peroxide 1,5\%, water, sorbitol, ethyl } \\
\text { alcohol 8\%, poloxamer 338, polysorbate 20, methyl } \\
\text { salicylate, menthol, sodium saccharin }\end{array}$ & $\begin{array}{c}\text { Colgate-Palmolive } \\
\text { Industrial LTDA }\end{array}$ \\
\hline Colgate Plax & Solution & $\begin{array}{r}\text { Sodium fluoride 0,05\%, cetylpyridinium chloride } \\
\text { 0,075, water, glycerin, propylene glycol, sorbitol, } \\
\text { poloxamer 407, potassium sorbate, sodium } \\
\text { FreshMint }\end{array}$ & Antiseptic \\
& & $\begin{array}{c}\text { Colgate-Palmolive } \\
\text { Industrial LTDA }\end{array}$ \\
\hline
\end{tabular}

The composite resin was added into the Teflon matrix with a particular instrument and condensed against the sidewalls and the bottom of the matrix. Subsequently, the composite resin was settled with a glass microscope slide approximately $1.0 \mathrm{~mm}$ thick. Then, the increment was immediately photoactivated for 20 seconds ${ }^{23}$ using the LED photoactivator device (Led 3M ESPE Elipar ${ }^{\mathrm{TM}}$ Deep cure-L) with an irradiance of $1470 \mathrm{~mW} / \mathrm{cm} 2$ and wavelength from 430 to $480 \mathrm{~nm}$ at distance zero from the specimen. The light intensity of the photoactivation device was gauged by the Ecel radiometer - Model RD, and read the light with predetermined intensity.

The specimens were wrapped in aluminum foil for $24 \mathrm{~h}$ to allow late polymerization and, afterwards, they were immersed in different antiseptic solutions with the aid of a universal holder (Metalic). The sample was immersed in a glass beaker containing $100.0 \mathrm{~mL}$ of mouthwash on a magnetic stirrer (Fisatom). The specimens were maintained using an orthodontic strand attached to the support that embraced its entire diameter.

The specimens were immersed in the respective mouthwashes for 12 hours, which is equivalent to one year of daily use of the solution for two minutes ${ }^{24,25}$.

Before and after their immersion in the mouthwash, the specimens were submitted to the surface roughness test. The Time Group Inc.-TR200 ${ }^{\text {TM }}$ Portable Roughness test was used in all specimens of each group, totalizing ten analyses of each group in this step. A utility wax was used to fix the specimen in each roughness test performed.

The surface roughness values were obtained before and after immersion in mouthwashes with alcohol (Colgate PlaxWhitening ${ }^{T M}$ ) and without alcohol (Colgate PlaxFreshMint $^{\mathrm{TM}}$ ) for the analysis.

Initially, a descriptive analysis of the sample was carried out, and the findings are provided in Table 3. 
Table 3. Descriptive statistics of the measurements for each type of resin.

\begin{tabular}{lcc}
\hline & Z350 $\mathbf{X T}^{*}$ & BF** \\
\hline Numberofvalues & 38 & 40 \\
\hline Minimum & 0,106 & 0,104 \\
\hline $25 \%$ Percentile & 0,174 & 0,393 \\
\hline Median & 0,234 & 0,443 \\
\hline $75 \%$ Percentile & 0,322 & 0,551 \\
\hline Maximum & 0,614 & 0,813 \\
\hline Mean & 0,246 & 0,474 \\
\hline Std. Deviation & 0,101 & 0,142 \\
\hline Std. Error & 0,016 & 0,022 \\
\hline Lower $95 \%$ Cl ofmean & 0,214 & 0,430 \\
\hline Upper $95 \%$ Cl ofmean & 0,278 & 0,518 \\
\hline
\end{tabular}

* Filtek $^{\text {TM }}$ Z350 XT (3M ESPE)

** Filtek ${ }^{\mathrm{TM}}$ Bulk Fill (3M ESPE)

In order to evaluate possible differences between groups, a two-way repeated measures ANOVA (linear mixed model) was fitted (data provided in Table 4). Both the main effects and the interactions of the predictor variables were evaluated. Pairwise testing was performed using Tukey's procedure. Normality and homoscedasticity assumptions were checked graphically. All tests considered a 5\%-significance level.

Table 4. P-values of the main effects and interactions of the predictor variables

\begin{tabular}{ll}
\hline VARIÁVEIS & VALOR $\mathbf{p}$ \\
\hline Resin & $<0,001$ \\
\hline Alcohol & 0,065 \\
\hline Time & 0,075 \\
\hline Resin : Alcohol & 0,715 \\
\hline Resin : Time & 0,148 \\
\hline Alcohol : Time & 0,843 \\
\hline \multicolumn{1}{c}{ Resin : Alcohol : Time } & 0,743 \\
\hline
\end{tabular}

: interações entre as variáveis

A priori, the size of the sample to achieve a minimum power of $80 \%$ was established based on a 95\%-confidence level to detect an effect size of $0.1 \mathrm{~mm}$ considering a conservative standard deviation of $0.1 \mathrm{~mm}$. The formula resulted in at least 16 samples per group. This number was rounded to 20 samples per group to increase precision. After the experiment, the post hoc statistical power of the observed effect size for each predictor variable was estimated through simulation with 2000 replications ${ }^{26}$. All statistical analyzes were performed using software R version 3.6.127.

\section{Results}

A significant difference was found only between composite resins $(p<0.001)$. The effect of the type of mouthwash and time (before and after) were only marginally 
significant. None of the interactions between the predictor variables were significant, as shown in Table 4.

It was noted that all Filtek ${ }^{\text {TM }}$ Bulk-Fill composite resins (3M ESPE) groups have significantly higher averages than the Filtek ${ }^{T M}$ Z350 XT composite resin (3M ESPE) groups. However, for the same composite resin, the groups do not differ from each other (Figure 1). The average difference in roughness between the two resins was $0.208 \mu \mathrm{m}$, with a $95 \%$ confidence interval between $0.103 \mu \mathrm{m}$ and $0.314 \mu \mathrm{m}$.

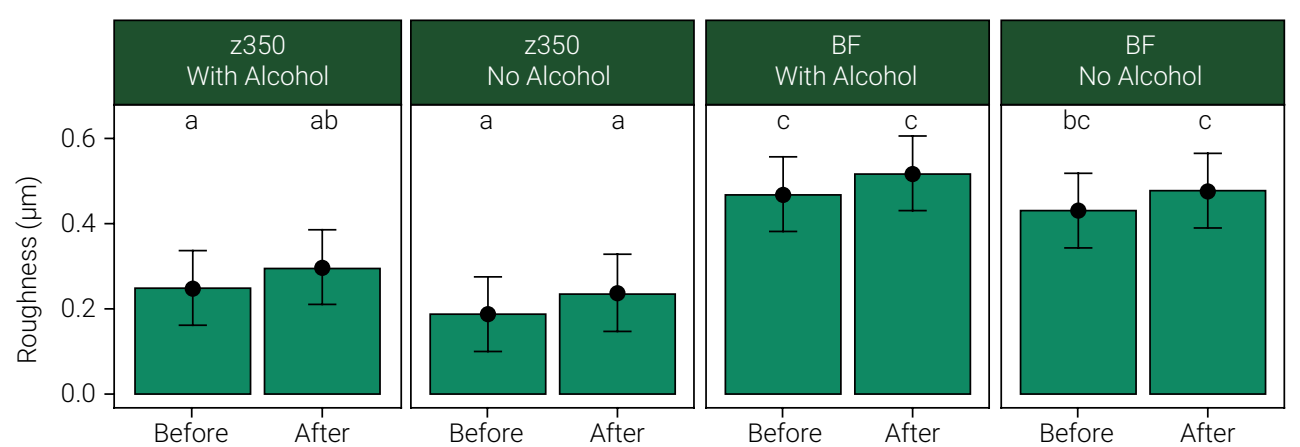

BF - Bulk-Fill

Figure 1. Roughness averages for each of the combinations of the three predictor variables. The error bars represent the $95 \%$ confidence interval for the population average. The letters above the groups specify multiple comparisons. Groups that share at least one letter are not significantly different from each other at $5 \%$ significance.

\section{Discussion}

The bulk-fill composite resins have been launched to shorten the time in clinical sessions, inserting increments of up to $5.0 \mathrm{~mm}$ in thickness. Thus, we intend to justify the clinical use of these new materials based on studies that assess their microhardness, polymerization shrinkage, and the contraction stress generated in the cavity walls ${ }^{28}$. However, the clinical longevity of restorations is directly related to several factors, including their surface roughness, and few works analyze the surface layer of bulk-fill composites.

According to the results of this study, the first null hypothesis that the use of mouthwashes does not interfere with the surface roughness of Filtek ${ }^{\text {TM }}$ Bulk-Fill Compounds (3M ESPE) and Filtek ${ }^{\text {TM }}$ Z350 XT (3M ESPE) has been confirmed. The second null hypothesis, which provides that differences in the chemical composition of Filtek ${ }^{\text {TM }}$ Bulk-Fill composite resin (3M ESPE) did not increase its surface roughness compared to conventional composite resins, was rejected.

The surface smoothness of the test specimens of this work was achieved with a glass slide, thus avoiding interference of any polishing techniques on results. The roughness tester measures high-frequency irregularities on the surface of a sample. The average roughness (RA) is the parameter used to analyze the surface ${ }^{13}$. Under the particular circumstances of this study, an outstanding difference was evidenced 
in the initial surface roughness of Filtek $^{\text {TM }}$ Bulk-Fill composite resin (3M ESPE) compared to the Filtek ${ }^{\mathrm{TM}}$ composite resin Z350 XT (3M ESPE) before immersion in mouthwashes.

Bulk-fill composite resins have been developed for exclusive use on posterior teeth and have differentiated monomers so that they can be used in single increments without causing damage to the bonding layer with the tooth structure. Studies show that non-fluid filled composite resins exhibit similar performance to conventional composites, making them a promising alternative in terms of mechanical performance ${ }^{29}$. Bulk-fill flow composites have the advantage of filling hard-to-reach angles in deep and narrow cavities, while larger cavities can be restored easily and more quickly using high-viscosity bulk-fill composites ${ }^{28}$.

According to the manufacturer, the two composite resins we evaluated in this study

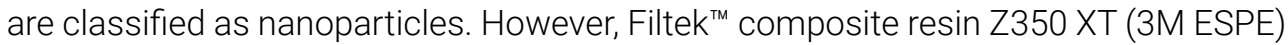
has medium size particles of 10 to 20nm, while Filtek ${ }^{\text {TM }}$ Bulk-Fill composite resin (3M ESPE) has, among its particles, ytterbium trifluoride with an average size of 10 to $100 \mathrm{~nm}$, which would justify the increased surface roughness by the increase of the particle size so. $^{30}$.

The findings in this study suggest that the composition of the organic matrix could influence surface roughness. In the case of Filtek ${ }^{\text {TM }}$ Bulk-Fill composite resin (3M ESPE), this influence can be explained by the incorporation of two novel methacrylate monomers: AUDMA (high molecular weight Urethane Dimethacrylate) and AFM (Additional Fragmentation Monomer), which promote relief of the polymerization shrinkage stress ${ }^{30}$. Both methacrylate monomers seem to attribute high viscosity to the bulk-fill composite so that it is easily inserted into the cavity, which may have contributed to its increased surface roughness.

Filtek $^{\text {TM }}$ composite resin Z350 XT (3M ESPE) has the highest percentage weight and volume filler compared to Filtek ${ }^{\text {TM }}$ Bulk-Fill (3M ESPE). According to Silva et al. $(2013)^{23}$, the physical and mechanical properties of composite resins are determined, among other factors, by the size, volume, and distribution of the filler parti-

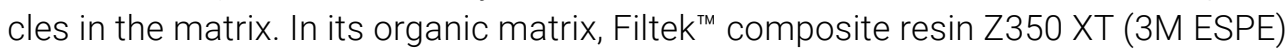
presents PEGDMA, which, together with TEGDMA, is used to adjust viscosity. The lower the viscosity of the organic matrix, the higher the amount of charge that can be incorporated, resulting in improved mechanical strength. This justifies the low

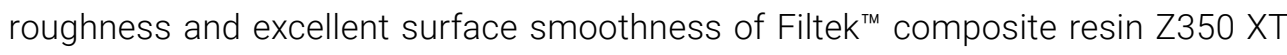
(3M ESPE) before immersion in rinses ${ }^{23}$.

The use of mouthwashes is an excellent tool for biofilm control. Often, the chemical resource used may be extended ${ }^{10}$. To simulate the clinical use of mouthwash for 2 minutes daily for one year, we immersed the specimens in both types of mouthwash for $12 h^{24,25}$.

The changes that mouthwashes can cause in the surface roughness of a restorative material depend on their composition. The causes of the changes to chemical structure and molecules of the polymer chains are critical to determine the degree of alteration by the aqueous environment on the restorative material ${ }^{12}$. 
Although oral antiseptics are widely recommended for plaque control, their excessive use can damage restorative materials due to the low $\mathrm{pH}$ and alcohol present in the solutions ${ }^{9}$. The excessive use causes sorption and hygroscopic expansion phenomena, derived from acid production methacrylate as a consequence of the degradation process of enzymatic hydrolysis ${ }^{9}$. Such factors can interfere in the polymeric matrix of the composite resins by the catalysis of the ester groups of the dimethacrylate monomers present in its composition ${ }^{11}$. However, the mouthwashes tested did not significantly interfere in the increase of the surface roughness of the tested composite resins, probably due to their high degree of conversion and consequent reduction in solubility ${ }^{31}$. In particular, the composite resin Filtek ${ }^{\text {TM }}$ Bulk-Fill (3M ESPE) has a large part of its composition with low solubility monomers, such as AUDMA, AFM, and $D D D M A^{30}$, which may also have contributed to the smallest change in its surface after immersion in the mouthwashes tested.

The $0.1 \mu \mathrm{m}$ difference used to estimate the sample size is considered a relatively small effect size when compared to other studies that found effect sizes larger than $1 \mu \mathrm{m}^{9}$. (In this study, the effect size for the difference between composite resins was $0.208 \mathrm{~mm}$ and, therefore, we had a statistical power of almost $100 \%$ to detect this difference. However, the difference between the periods and the types of mouthwash was less than $0.04 \mathrm{~mm}$, which results in the statistical power of less than $50 \%$. For this insignificant difference, it is not possible to distinguish whether the lack of a significant result is due to the sample size or if the difference does not exist. Regardless of the cause, this difference may not have clinical significance.

The results of this in-vitro work are consistent with other studies, such as that of Lucena et al. (2010) ${ }^{12}$, in which the Filtek ${ }^{\text {TM }}$ composite resin Z350 XT (3M ESPE) did not present a significant difference in surface roughness between mouthwashes either with or without alcohol.

Similarly, in another study, the surface roughness of restorative materials was evaluated after immersion in mouthwashes, leading to the conclusion that the mouthwashes do not promote a significant change in the surface roughness of Filtek ${ }^{\mathrm{TM}} \mathrm{com}^{-}$ posite resin Z350 XT (3M ESPE) ${ }^{9}$.

The clinical effects of mouthwashes on composite resins may depend on some other reasons, such as plaque, beverages, eating habits, and mouthwash, which cannot be reproduced in vitro. This is a limitation of this study. These factors, whether acting together or separately, can influence the mechanical and physical characteristics and interfere in the longevity of the restorative treatment ${ }^{11}$. In this study, the samples were adequately polymerized in contact with the tip of the photoactivator, whereas in clinical practice, especially in posterior teeth, this is not possible.

Furthermore, as a limitation of the present study, the flat surface of the specimens cannot reproduce the clinical situation, such as the occlusal region, which has concave and convex areas. Besides, there was difficulty in carrying out the stabilization of the specimens and the agitation of the mouthwashes so that the clinical situation of daily rinsing was simulated correctly. The results of this in-vitro study indicated intermaterial relationships, but they cannot be fully extrapolated to clinical practice. Additional in-vitro studies using scanning electron microscopy, 
mechanical cycling, and in-vivo longitudinal studies should be performed to predict the clinical longevity of bulk-fill composites.

Since there are no findings in literature similar to this study, the behavior of the high viscosity Filtek ${ }^{\mathrm{TM}}$ Bulk-Fill composite resin (3M ESPE) could not be clinically predicted. Further studies comparing Bulk-Fill composite resins are required to assess whether the surface roughness found is acceptable for clinical use.

In view of the limitations of the study, the use of mouthwashes does not interfere with the surface roughness of the tested composite resins, but the composite resin Filtek Z350 XT (3M ESPE) presents a surface with less roughness, being, therefore, more suitable for clinical use.

\section{Acknowledgements}

We thank the technicians of the Material Engineering Laboratory of the Centro Universitário Newton Paiva - Belo Horizonte.

\section{REFERENCES}

1. Ali Z, Eliyas S, Vere JW. Choosing the right dental material and making sense of the options: evidence and clinical recommendations. Eur J Prosthodont Restor Dent. 2015 Sep;23(3):P150-62.

2. Khalaf ME, Alomari QD, Omar R. Factors relating to usage patterns of amalgamand resin composite for posterior restorations - a prospective analysis. J Dent. 2014 Jul;42(7):785-92. doi: 10.1016/j.jdent.2014.04.010.

3. Kapoor N, Bahuguna N, Anand S. Influence of composite insertion technique on gap formation. J Conserv Dent. 2016;19(1):77-81. doi: 10.4103/0972-0707.173205.

4. Chandrasekhar V, Rudrapati L, Badami L, Tummala M. Incremental techniques in direct composite restoration. J Conserv Dent. 2017;20(6):386-91. doi: 10.4103/JCD.JCD_157_16.

5. Rizzante FAP, Mondelli FRFL, Furuse AY, Borges AFS, Mendonça G, Ishikiriama SK. Shrinkage stress and elastic modulus assessment of bulk-fill composites. J Appl Oral Sci. 2019 Jan 7;27:e20180132. doi: 10.1590/1678-7757-2018-0132.

6. Van Ende A, De Munck J, Lise DP, Van Meerbeek B. Bulk Fill Composites: a review of the current literature. J Adhes Dent. 2017;19(2):95-109. doi: 10.3290/j.jad.a38141.

7. Festuccia MSCC, Garcia LF, Cruvinel DR, Pires-de-Souza FCP. Color stability, surface roughness and microhardness of composites submitted to mouthrinsing action. J Appl Oral Sci. 2012;20(2):200-5. doi: 10.1590/s1678-77572012000200013.

8. Sadaghiani L, Wilson MA, Wilson NH. Effect of selected mouthwashes on the surface roughness of resin modified glass-ionomer restorative materials. Dent Mater. 2007 Mar;23(3):325-34. doi: 10.1016/j.dental.2006.01.024.

9. Bohener LOL, Godoi APT, Ahmed AS, Tortamano Neto P, Catirse ABCEB. Surface roughness of restorative materials after immersion in mouthwashes. Eu J Gen Dent. 2016;5(3):111-4. doi: 10.4103/2278-9626.189255.

10. Borges AH, Pedro FLM, Semenoff TDV, Porto N, Semenoff-Segundo A, Buzelle SL. Antimicrobial effectiveness of different trademarks mouthwashes with and without alcohol against different organisms: in vitro study. Rev Odonto Cienc. 2010; 25(2):178-81. doi: 10.1590/S1980-65232010000200014. 
11. Miranda DA, Bertoldo CES, Aguiar FHB, Lima DANL, Lovadino JR. Effects of mouthwashes on Knoop hardness and surface roughness of dental composites after different immersion times. Braz Oral Res. 2011;25(2):168-73. doi: 10.1590/s1806-83242011000200012.

12. Lucena MCM, Gomes RVS, Santos MCMS. [Assessment surface roughness of the flwable resin filtek Z350 3M/ espe exposed to mouthrinses with and without alcohol]. Odontol Clin Cient. 2010;9(1):59-64. Portuguese.

13. Cruz J, Sousa T, Cavalheiro A, Pequeno A, Romão B, Coito C. [Surface roughness analysis and microhardness of six resin composites]. Rev Port Estomatol Med Dent Cir Maxilofac. 2016;57(1):38-45. doi: 10.1016/j.rpemd.2015.11.010. Portuguese.

14. Nascimento AS, Rodrigues JFB, Torres RHN, Santos KO, Fook MVL, Albuquerque MS, et al. Physicomechanical and thermal analysis of bulk-fill and conventional composites. Braz Oral Res. 2019 Mar 18;33:e008. doi: 10.1590/1807-3107bor-2019.vol33.0008.

15. Tanthanuch S, Kukiattrakoon B, Eiam-O-Pas K, Pokawattana K, Pamanee N, Thongkamkaew W, et al. A surfasse changes of various bulk-fill resin-based composites after exposure to diferente food-simulating liquid and beverages. J Esthet Restor Dent. 2018 Mar;30(2):126-35. doi: $10.1111 /$ jerd. 12349 .

16. de Brito O, de Oliveira I, Monteiro G. Hydrolytic and biological degradation of bulk-fill and self-adhering resin composites. Oper Dent. 2019;44(5):E223-33. doi: 10.2341/17-390-L.

17. Lai G, Zhao L, Wang J, Kunzelmann KH. Surface properties and color stability of incrementally-filled and bulk-fill composites after in vitro toothbrushing. Am J Dent. 2017 oct;30(5):262-6.

18. Somacal DC, Manfroi FB, Monteiro M, Oliveira SD, Bittencourt HR, Borges GA, et al. Effect of pH cycling followed by simulated toothbrushing on the surface roughness and bacterial adhesion of bulk-fill composite resins. Oper Dent. 2020;45(2):209-18. doi: 10.2341/19-012-L.

19. Queiroz RS, Lima JPM, Malta DAMP, Rastelli ANS, Cuin A, Porto-Neto ST. Changes on transmittance mode of different composite resins. Mat Res. 2009;12(2):127-32. doi: 10.1590/S1516-14392009000200003.

20. Nahsan FPS, Ueda JK, Silva JO, Schmitt VL, Naufel FS, Formighieri LA, et al. [Color stability of resin composites after immersion in coffee, water and chlorhexidine mouthrinse]. Rev Bras Pesq Saude. 2009;11(2):13-7. Portuguese.

21. Kabbach W, Bevilacqua FM, Campos JADB, Dinelli W, Porto-Neto ST. [Evaluation of the surface roughness of composite resin after the action of immediate bleaching agentes]. Rev Uniara. 2005/2006;17(18):239-48. Portuguese.

22. Jardim PS, Miranda CB, Candido MSM, Lima DM. [Comparative analysis of translucency of enamel and different composite resins microparticles]. Cienc Odontol Bras. 2002;5(3):18-24. doi: 10.14295/bds.2002.v5i3.174. Portuguese.

23. Silva AEM, Scarpelli MM, Silva JS. [Evaluation of microhardness and polishing of three photoactivated composites by two types of light: in vitro study]. Odontol Clin-Cient. 2013;12(2):123-7. Portuguese.

24. Gurgan S, Onen A, Koprulu H. In vitro effects of alcohol containing and alcohol-free mouthrinses on microhardness of some restorative materials. J Oral Rehabil. 1997 Mar;24(3):244-6.

25. Aragão GS, Falcão RM, Durães I, Bezerra RB. [Influence of mouthwashes on surface roughness of a composite resin]. Rev Bahiana Odontol. 2016;7(4):243-52. doi: 10.17267/2596-3368dentistry.v7i4.936. Portuguese.

26. Green P, MacLeod CJ. SIMR: an R package for power analysis of generalized linear mixed models by simulation. Methods Ecol Evol. 2016;7(4):493-8. doi: 10.1111/2041-210X.12504.

27. R Core Team. The R Project for Statistical Computing. R: A language and environment for statistical computing. 2019. Available from: https://www.R-project.org. 
28. Ilie N, Schöner C, Bücher K, Hickel R. An in-vitro assessment of the shear bond strength of bulk-fill resin composites to permanent and deciduous teeth. J Dent. 2014 Jul;42(7):850-5. doi: 10.1016/j.jdent.2014.03.013.

29. Papadogiannis D, TolidisK, Gerasimou P, Lakes R, Papadogiannis Y. Viscoelastic properties, creep behavior and degree of conversion of bulk fill composite resins. Dent Mater. 2015 Dec;31(12):1533-41. doi: 10.1016/j.dental.2015.09.022.

30. 3M Science. Applied to Life ${ }^{\mathrm{TM}}$. Available from: http://solutions.3m.com.br/wps/portal/3M/pt_BR/Skin WoundCare/Home/HealthCareAcademy/Odontologia/MateriaisTecnicos?WT.mc_id=www.3 m.com. $\mathrm{br} /$ healthcareacademy.

31. Cebe MA, Cebe F, Cengiz MF, Cetin AR, Arpag OF, Ozturk B. Elution of monomer from different bulk fill dental composite resins. Dent Mater. 2015 Jul;31(7):e141-9. doi: 10.1016/j.dental.2015.04.008. 